\title{
MAPEAMENTO DA PRECIPITAÇÃO PLUVIOMÉTRICA NO BIOMA CERRADO DO ESTADO DO MATO GROSSO
}

\author{
RAINFALL MAPPING OF CERRADO BIOME IN THE STATE OF MATO GROSSO \\ CARTOGRAFIA DE PRECIPITACIONES EN EL BIOME DEL CERRADO \\ EN EL ESTADO DE MATO GROSSO
}
Francisco Fernando Noronha Marcuzzo - Companhia de Pesquisa de Recursos Minerais / Serviço Geológico do Brasil - Goiânia - Goiás - Brasil
francisco.marcuzzo@cprm.gov.br

Hudson Moraes Rocha - Universidade Federal de Goiás - Jataí - Goiás - Brasil sauhudson@gmail.com
Denise Christina de Rezende Melo - Companhia de Pesquisa de Recursos Minerais / Serviço Geológico do Brasil - Goiânia - Goiás - Brasil
denise.melo@cprm.gov.br

\section{Resumo}

A análise do comportamento das chuvas se torna importante, uma vez que possibilita detectar tendências ou alterações no clima, em escalas local, regional ou global. 0 presente trabalho mapeou a distribuição da precipitação pluviométrica no bioma Cerrado do estado do Mato Grosso. Utilizaram-se dados de 33 estações pluviométricas distribuídas no bioma do Cerrado mato-grossense, com dados de 30 anos, de 1977 a 2006. Foram elaborados mapas de chuvas com 0 auxílio de isoietas e aplicado 0 cálculo do Índice de Anomalia de Chuva (IAC) para a classificação dos períodos secos ou úmidos, de acordo com a média local, organizadas em médias temporais mensal, anual e sazonal da precipitação. 0 método de interpolação utilizado foi o Topo to Raster, em que se utiliza o método multigrid simples para minimizar a equação em resoluções cada vez melhores, respeitando restrições dos elementos físicos. 0 s resultados da distribuição pluviométrica mostram uma grande variação nos índices precipitados, sendo que o extremo noroeste e norte têm os maiores volumes de chuvas e 0 sul da área de estudo apresenta os menores índices pluviométricos. Com a análise do IAC para o período de estudo, verificou-se que existe um maior número de anos secos que anos úmidos para o período estudado. Palavras-chave: precipitação pluviométrica, Cerrado, índice de anomalia de chuva, pluviometria.

\section{Abstract}

The behavior of rainfall becomes important, since it allows to detect trends or changes in climate, regional or local scales. The study mapped the distribution of rainfall in the Cerrado of Mato Grosso. We used data from 33 rainfall stations distributed in the Cerrado, with data for 30 years, from 1977 to 2006. Maps were drawn with the aid of rainfall isoline and applied to calculate the Rainfall Anomaly Index (RAI) for the classification of dry or wet periods, according to the average local, organized in a temporal average monthly, annual and seasonal precipitation. The interpolation method was used to Raster Top, which uses a multigrid simple equation to minimize the ever-improving resolutions respecting constraints of the physical elements that make up the landscape. The results of the rainfall distribution shows a wide variation in rates precipitated, and the extreme northwest and north have the largest volumes of rain and south of the lowest rainfall biome. With the analysis of the RAl for the period of study, it was found that a larger number of dry years than wet years for the period studied.

Key words: rainfall, Cerrado, rainfall anomaly index, pluviometric. 
Resumen

El comportamiento de la lluvia se vuelve importante, ya que permite detectar tendencias o cambios en el clima, regional o local escalas. El estudio describe la distribución de las precipitaciones en el Cerrado de Mato Grosso. Se utilizaron los datos de 33 estaciones pluviométricas distribuidas en el Cerrado, con los datos durante 30 años, desde 1977 hasta 2006. Los mapas fueron elaborados con la ayuda de isolíneas de lluvia y aplicada para calcular el Índice de Anomalia de la Lluvia (IAL) para la clasificación de los períodos secos o húmedos, según la media de la zona, organizados en un promedio temporal mensual, la precipitación anual y estacional. El método de interpolación, se utiliza para Raster Top, que utiliza una red multi-ecuación simple para reducir al mínimo la mejora constante de las resoluciones respetando los límites de los elementos físicos que componen el paisaje. Los resultados de la distribución de las precipitaciones muestra una amplia variación en las tasas de precipitado, y extremo noroeste y norte, tienen los mayores volúmenes de lluvia y el sur del bioma de menor pluviosidad. Con el análisis de la IAL para el período de estudio, se constató que un mayor número de años de sequía de los años lluviosos del período estudiado.

Palabras clave: precipitación, cerrado, índice de anomalia de la lluvia, pluviometria.

\section{Introdução}

O uso de Sistemas de Informação Geográfica (SIG) tem sido de fundamental importância na representação espacial e temporal em estudos de distribuição espacial de chuvas, porque permite uma boa aproximação da realidade climática da área estudada. Braz et al. (2009, p. 55), em um estudo no qual utilizou o SIG para verificar a distribuição temporal e espacial das chuvas na Bacia Barra Seca (ES) e três métodos matemáticos, que foram a média aritmética, polígonos de Thiessen e Interpolação - Inverso da Distância (IDW), concluiu que apesar de apresentarem resultados semelhantes, é sugerida a utilização do interpolador IDW para representação da distribuição das chuvas, devido à produção de mapas contínuos e heterogêneos.

Coutinho (2005, p. 49), em estudo de verificação da dinâmica das queimadas do estado de Mato Grosso, refere-se a três grandes macrounidades climáticas da região, que seriam: Clima Equatorial Continental Úmido, Clima Subequatorial Continental Úmido e Clima Tropical Continental Alternadamente Úmido e Seco.

Rosa et al. (2007, p. 148), ao analisar a distribuição e variabilidade pluviométrica anual na porção centro-oeste do estado de Mato Grosso, entre os anos de 1985 a 1995, com a espacialização da chuvas em mapas de isoietas, identificou que a variabilidade pluviométrica foi bem irregular nas porções oeste e sul onde as chuvas ocorreram em maior quantidade, sendo que as menores quantidades chuvosas registraram-se nas porções leste e norte. 
Dentre vários métodos estatísticos utilizados em estudos de precipitação pluviométrica, o Índice de Anomalia de Chuva (IAC) se destaca, por permitir o acompanhamento climático com efetuação de comparações entre as condições atuais e os valores históricos de chuvas, e também para o entendimento da distribuição espacial e temporal entre os períodos secos e úmidos. Assim, conhecendo o IAC, órgãos governamentais ou entidades privadas podem utilizar de forma sustentável os recursos naturais como, por exemplo, no zoneamento agrícola ou no planejamento regional, uma vez que há um conhecimento parcial da dinâmica da chuva.

Araújo et al. (2009, p. 97), utilizando IAC em estudo da bacia do rio Paraíba/PB, verificou que a variação temporal do IAC dos anos secos de 1987 e 1990 é condizente com o regime pluviométrico da região, sendo que nos períodos úmidos de 1984 a distribuição do IAC é irregular, principalmente na estação chuvosa. Já a variação espacial do IAC dos anos secos de 1987 e 1990 demonstrou índices que variam de seco a extremamente seco, principalmente no ano de 1990, sobre a influência do El niño na região.

Este trabalho analisará a variação espacial, temporal e sazonal da precipitação pluvial no estado do Mato Grosso, utilizando séries históricas de chuvas e o cálculo estatístico do IAC, para aferir qualitativamente os dados utilizados.

Caracterização da vegetação, clima e dos mecanismos de formação de chuvas no bioma Cerrado do estado do Mato Grosso

O bioma Cerrado do estado do Mato Grosso está localizado na região Centro-Oeste do Brasil e ao centro do estado do Mato Grosso (IBGE, 2009, mapa), representa $39 \%$ da área total de $903.357,908 \mathrm{~km}^{2}$ da superfície do estado, limitando-se entre os paralelos $10^{\circ}$ a $19^{\circ} \mathrm{Sul}$ e os meridianos $51^{\circ}$ a $62^{\circ}$ Oeste (Figura 1).

Os principais mecanismos atmosféricos que atuam no CentroOeste e em específico o bioma Cerrado do Mato Grosso são a massa polar atlântica que é caracterizada pelo acúmulo do ar polar e a massa de ar equatorial continental, presente entre a primavera e o verão, advinda do efeito térmico e da elevada umidade. Essa última se desloca para o interior do país no sentido noroeste para sudeste, provocando chuvas. A primeira massa polar atlântica - atua com maior frequência no inverno, no sentido 
sul para o norte, e favorece as quedas de temperatura e estiagem (NIMER, 1989, p. 23-24).

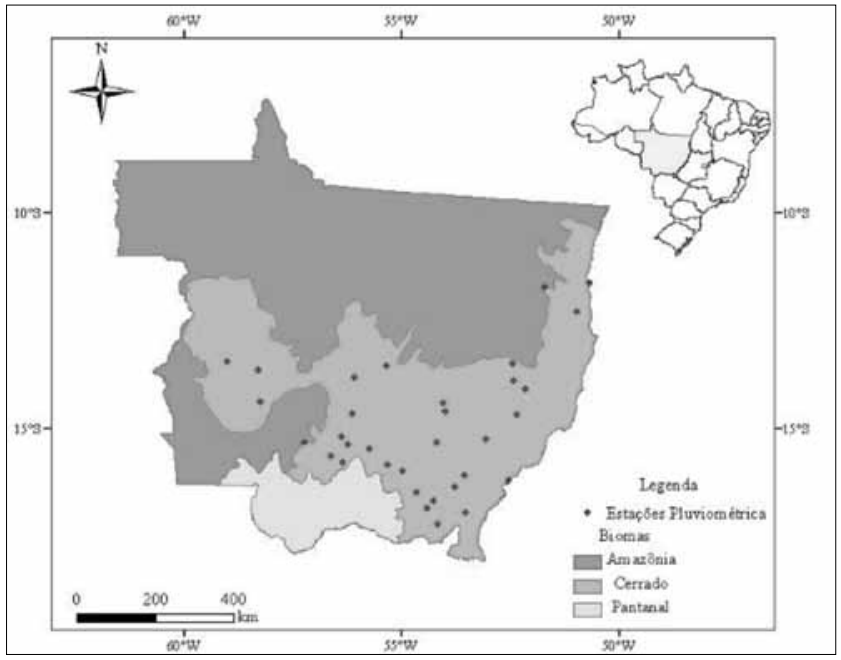

Figura 1 - Localização das estações pluviométricas com 30 anos de dados diários no bioma Cerrado no estado do Mato Grosso.

Dados utilizados e estatística de anomalias na distribuição temporal das chuvas

Os dados diários de precipitação pluvial foram obtidos da Companhia de Pesquisa de Recursos Minerais (CPRM) - Serviço Geológico do Brasil e pelas estações meteorológicas da base de dados da Agência Nacional das Águas (ANA).

Utilizaram-se dados de 33 estações pluviométricas distribuídas no bioma do Cerrado em Mato Grosso (Figura 1). Os dados pluviométricos foram copilados, tratados estatisticamente, consistidos e organizados em planilhas eletrônicas, com informação diária, mensal, anual e sazonal, para posterior mapeamento.

Para a classificação dos períodos secos ou úmidos de acordo com a média local, foram calculadas as médias temporais mensal, anual e sazonal da precipitação para o período de estudo, necessárias para o cálculo do Índice de Anomalia de Chuva (IAC). Assim, utilizou-se neste trabalho o IAC desenvolvido e testado por Rooy (1965, p. 20), o qual é apresentado pelas seguintes equações (Quadro 1): 
$I A C=3\left[\frac{(N-\bar{N})}{(\bar{M}-\bar{N})}\right]$, para anomalias positivas

$I A C=-3\left[\frac{(N-\bar{N})}{(\bar{X}-\bar{N})}\right]$, para anomalias negativas

em que, $N$ - precipitação mensal atual (mm.mês-1 $) ; \bar{N}$ - precipitação média mensal da série histórica (mm.mês $\left.{ }^{-1}\right) ; \bar{M}$ - média das dez maiores precipitações mensais da série histórica $\left(\mathrm{mm} . \mathrm{mês}^{-1}\right)$ e $\bar{X}$ - média das dez menores precipitações mensais da série histórica (mm.mês $\left.{ }^{-1}\right)$.

Quadro 1 - Classificação da pluviosidade para o estado do Mato Grosso, segundo o IAC.

\begin{tabular}{|l|l|}
\hline Índice de Anomalia de Chuva (IAC) & Classificação da Pluviosidade \\
\hline$X \geq 4$ & Extremamente Chuvoso \\
\hline$X \geq 2$ e $X<4$ & Muito Chuvoso \\
\hline$X>0$ e $X<2$ & Chuvoso \\
\hline$X=0$ & Nem Chuvoso e Nem Seco (Sem Anomalia) \\
\hline$X<0$ e $X>-2$ & Seco \\
\hline$X \leq-2$ e $X>-4$ & Muito Seco \\
\hline$X \leq-4$ & Extremamente Seco \\
\hline
\end{tabular}

Fonte: Rooy, 1965.

Interpolação matemática

A função Topo to Raster é um método de interpolação baseado no programa ANUDEM desenvolvido por Hutschinson, que foi especificamente feito para a criação de Modelos de Elevação Digital (DEM) hidrologicamente corretos. O programa interpola os dados de elevação em uma grade regular, de modo iterativo, gerando grades sucessivamente menores, minimizando a rugosidade (roughness penalty) e a soma dos quadrados dos resíduos (diferenças das elevações medidas e calculadas pela função).

Cada elevação em um determinado local é dada por:

$$
z_{i}=f\left(x_{i}, y_{i}\right)+w_{i} \varepsilon_{i}
$$

em que, $f(x, y)$ é a função de interpolação, definida por uma função B-spline, cada $w_{i}$ é uma constante positiva que representa o erro de discretização do 
ponto $i$ e cada $\varepsilon_{i}$ é uma amostra de uma variável aleatória de média zero e desvio padrão igual a um.

Assumindo que cada ponto está localizado aleatoriamente dentro da célula do modelo, a constante $w_{i}$ é definida por:

$$
\begin{aligned}
& w_{i}=h s_{i} / \sqrt{12} \\
& \sum_{i=1}^{n}\left[\left(z_{i}-f\left(x_{i}, y_{i}\right)\right) / w_{i}\right]^{2}+\lambda J(f)
\end{aligned}
$$

em que, $h$ é o espaçamento da grade; si é a medida de inclinação da célula da grade associada com o ponto $\left(x_{i}, y_{i}\right)$. A função $f(x, y)$ é então estimada resolvendo uma aproximação na grade regular via método das diferenças finitas que minimiza a somatória. A constante $w_{i}$ varia com cada iteração, em uma característica adaptativa local (locally adaptive feature), já que a cada iteração do programa um novo valor de inclinação (si) é disponibilizado para cada célula da grade conforme o método iterativo avança.

O programa utiliza o método multigrid simples para minimizar a equação em resoluções cada vez melhores, começando de uma grade inicial larga até uma grade que tenha resolução definida pelo usuário, respeitando restrições que garantem uma estrutura conectada.

\section{Distribuição dos valores pluviométricos}

A distribuição dos valores pluvial da média mensal e anual, com base nos dados da série histórica de 1977 a 2006, registrados em 33 estações pluviométricas distribuídas na área de estudo, apresenta uma variação significativa da precipitação, sendo que as maiores variações são observadas nos índices mensais.

Os meses de janeiro e fevereiro (Figura 2) compõem o período chuvoso do bioma, quando a amplitude pluviométrica foi de $150 \mathrm{~mm}$ e 375 $\mathrm{mm}$. Verifica-se, assim, que os meses de janeiro e fevereiro apresentaram médias pluviométricas acima da média do período chuvoso, superior a $150 \mathrm{~mm}$, com tendência a aumento dos índices pluviais no sentido sul para o norte do bioma. 


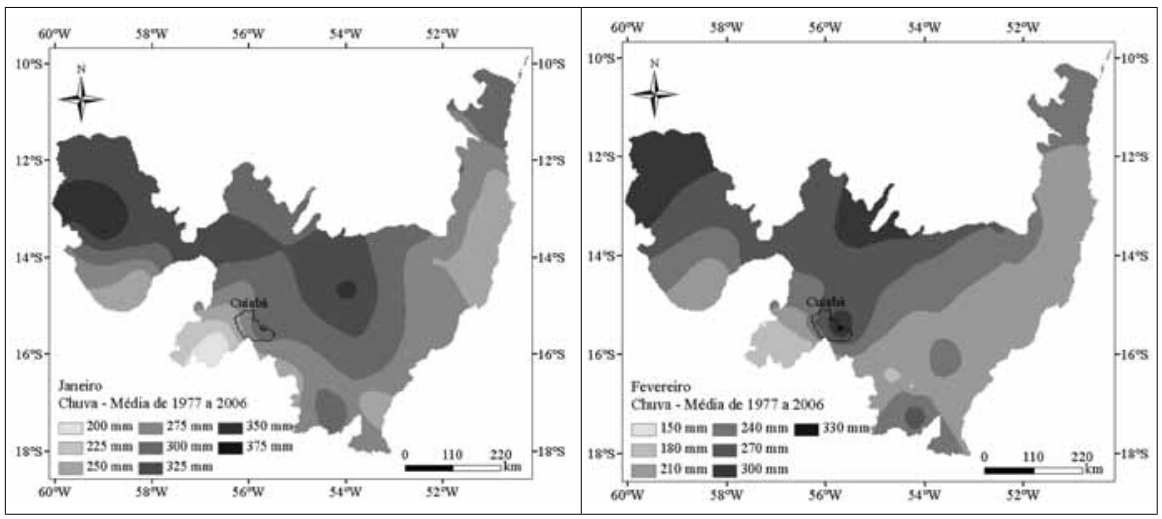

Figura 2 - Precipitação pluviométrica média mensal nos meses de janeiro e fevereiro, para 0 estado de Mato Grosso, referente ao período histórico de 1977 a 2006.

A Figura 3, meses de março e abril, é marcada pelo enfraquecimento da atuação da massa de ar equatorial continental e maior frequência da massa de ar polar, com consequente diminuição dos valores médios pluviométricos, em que as chuvas variaram de 50 a $308 \mathrm{~mm}$.

No mês de abril, acentua-se o decréscimo dos índices pluviométricos, variando de 50 a $175 \mathrm{~mm}$, quando os valores elevados de precipitação ocorreram a noroeste e nordeste do bioma Cerrado de 150 a $175 \mathrm{~mm}$ e os menores de 50 a $75 \mathrm{~mm}$ a sudeste do bioma no estado.

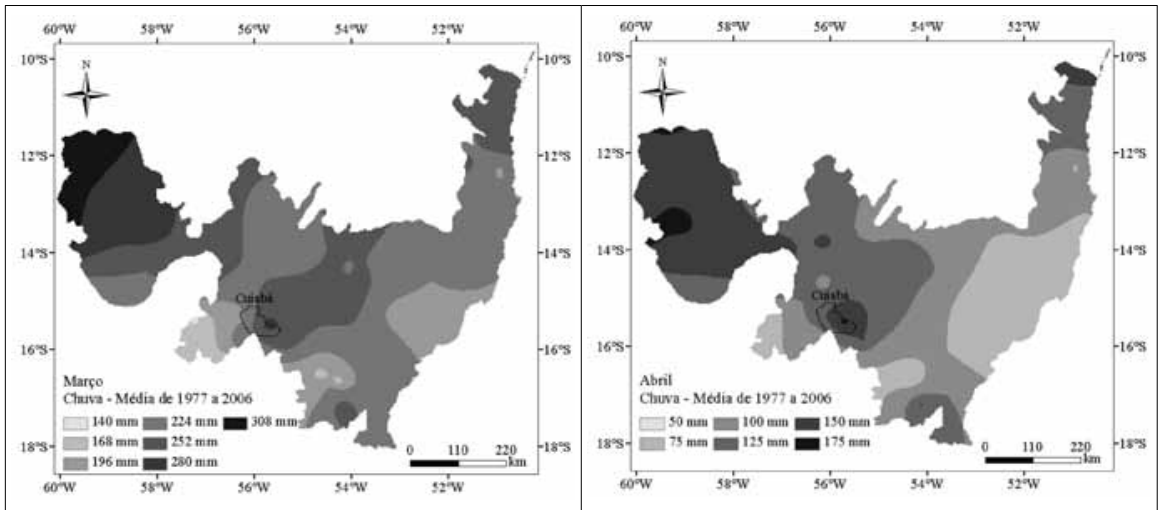

Figura 3 - Precipitação pluviométrica média mensal nos meses de março e abril, para o estado de Mato Grosso, referente ao período histórico de 1977 a 2006. 
A Figura 4, mês de maio, corresponde ao início da estação seca em Mato Grosso, com uma diminuição nos índices pluviais, que variaram de 18 a $81 \mathrm{~mm}$. Os meses de junho, julho e agosto (Figura 4 e 5) coincidem com o inverno no estado do Mato Grosso, que favorece as quedas de temperatura e a estiagem. Rosa et al. (2007, p. 134) observa que, nessa época, em Mato Grosso, as chuvas são raras com precipitações de quatro a cinco dias nos meses de junho, julho e agosto, concentrando totais entre 20 e $80 \mathrm{~mm}$ de pluviosidade. Assim, as ocorrências de chuvas no extremo norte do estado de Mato Grosso são consequências do sistema de circulação perturbada de W (IT).

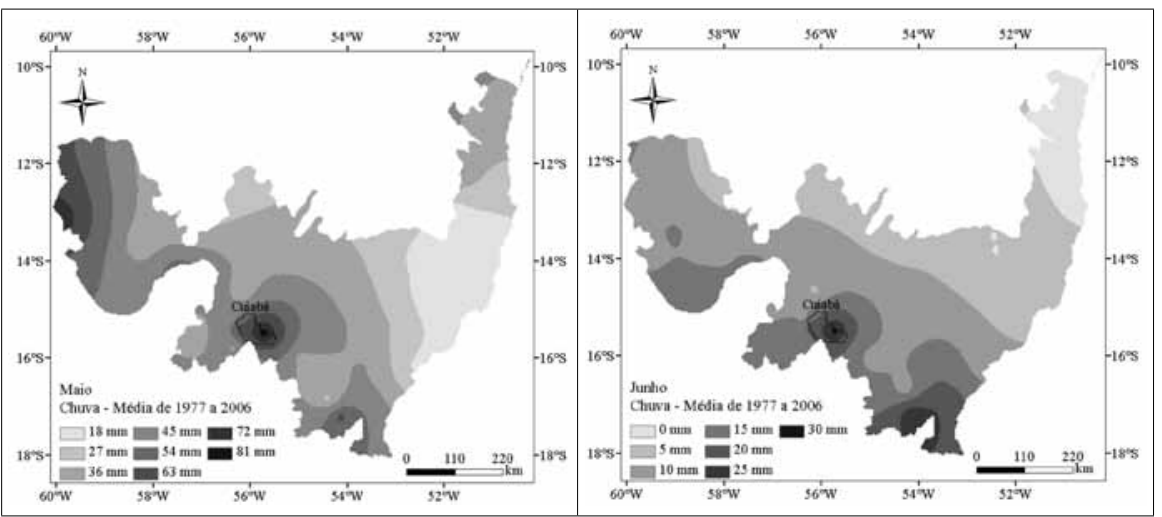

Figura 4 - Precipitação pluviométrica média mensal nos meses de maio e junho, para o estado de Mato Grosso, referente ao período histórico de 1977 a 2006.

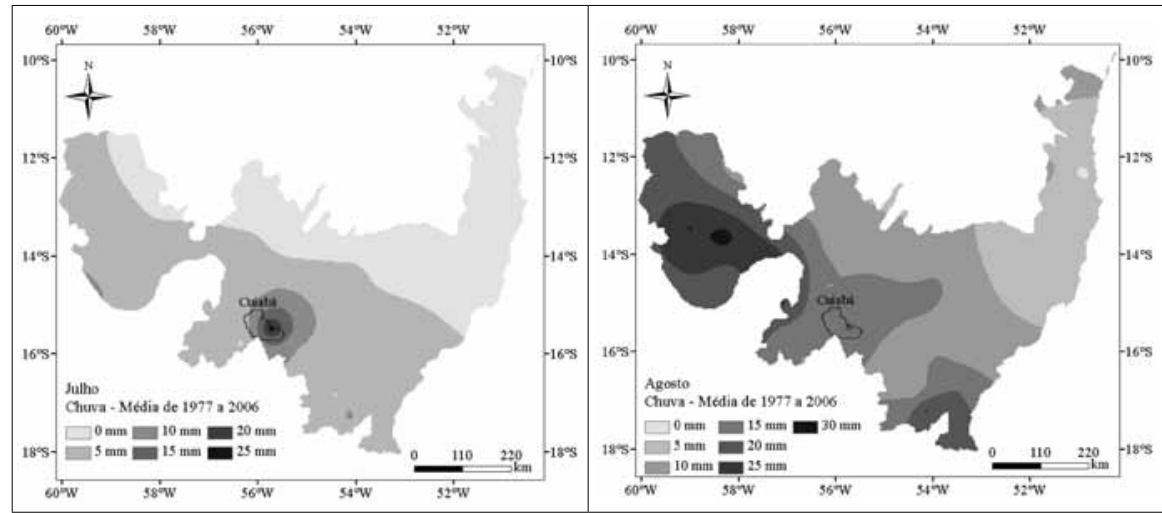

Figura 5 - Precipitação pluviométrica média mensal nos meses de julho e agosto, para o estado de Mato Grosso, referente ao período histórico de 1977 a 2006. 
O mês de setembro (Figura 6) representa o período de transição da estação seca para a estação chuvosa. Segundo Rosa et al. (2007, p. 135), o trimestre de setembro a novembro é caracterizado por temperaturas altas, provindas do aquecimento do equinócio da primavera (outubro - novembro).

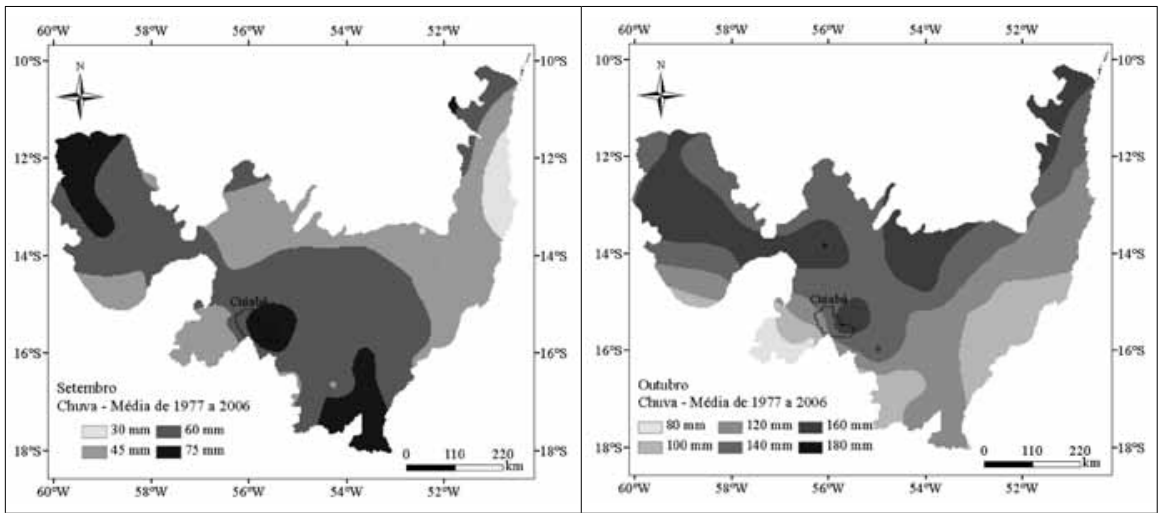

Figura 6 - Precipitação pluviométrica média mensal nos meses de setembro e outubro, para 0 estado de Mato Grosso, referente ao período histórico de 1977 a 2006.

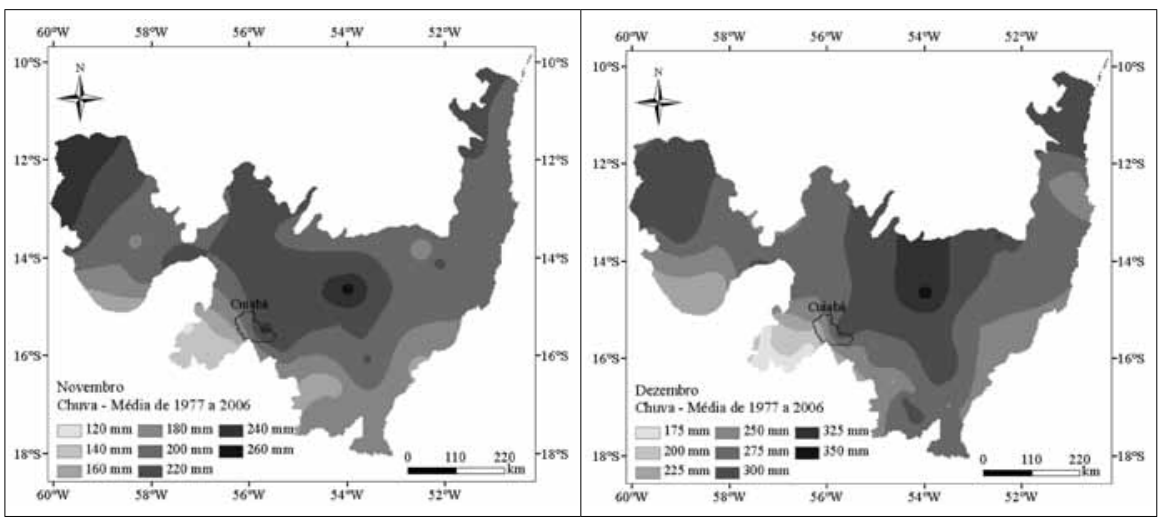

Figura 7 - Precipitação pluviométrica média mensal nos meses de novembro e dezembro, para 0 estado de Mato Grosso, referente ao período histórico de 1977 a 2006.

A principal característica do período de outubro a novembro é a pouca ocorrência inicial de precipitações com o aumento gradativo do 
regime pluviométrico, coincidindo com o início do verão no mês de dezembro, o que podemos verificar nas Figuras 6 e 7 .

O mês de dezembro compõe o período mais chuvoso (Figura 7) do estado do Mato Grosso, junto com janeiro, fevereiro e março, e apresenta comportamento pluvial similar aos demais meses dessa estação chuvosa.

Análise da precipitação pluviométrica dos períodos seco e úmido para o estado do Mato Grosso no bioma Cerrado

A Figura 8 apresenta o índice da concentração pluviométrica da média anual dos períodos chuvoso, de setembro a abril, e seco, de maio a agosto. Nota-se que, no período chuvoso, o índice pluviométrico variou de $120 \mathrm{~mm}$ a $240 \mathrm{~mm}$, e a concentração pluvial da média anual do período seco de maio a agosto teve uma variação de 5 a $40 \mathrm{~mm}$. Conforme Rosa et al. (2007, p. 135), a porção norte do estado do Mato Grosso apresenta os maiores valores de precipitação com valores superiores a $2750 \mathrm{~mm}$, diminuindo nas direções leste, oeste e sul do estado, o que resulta em uma precipitação que se distribui de forma irregular durante todo o ano.

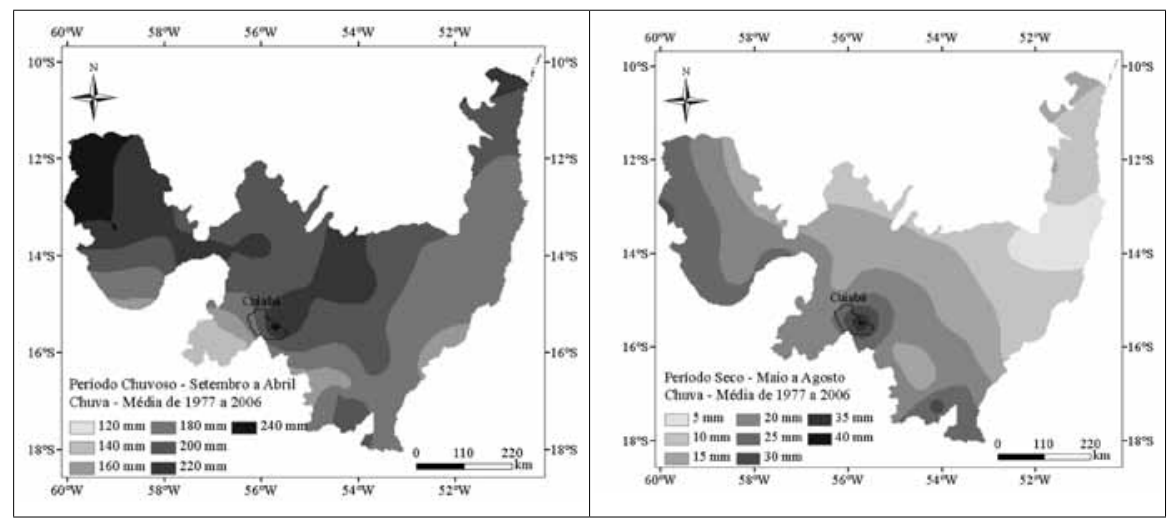

Figura 8 - Precipitação pluviométrica média para o período chuvoso (setembro a abril) e seco (maio a agosto), para o estado de Mato Grosso, referente ao período histórico de 1977 a 2006.

Observa-se na Figura 9 o total de precipitações dos anos de 1977 a 2006. No período úmido de setembro a abril, o total pluviométrico superou os $2.000 \mathrm{~mm}$, sendo que a porção noroeste teve os maiores totais 
pluviométricos. O período seco estendeu-se de maio a agosto e a menor pluviosidade total acumulada não ultrapassou os $150 \mathrm{~mm}$ para o período de 1977 a 2006, sendo a porção leste a menos favorecida pelo índice pluviométrico.

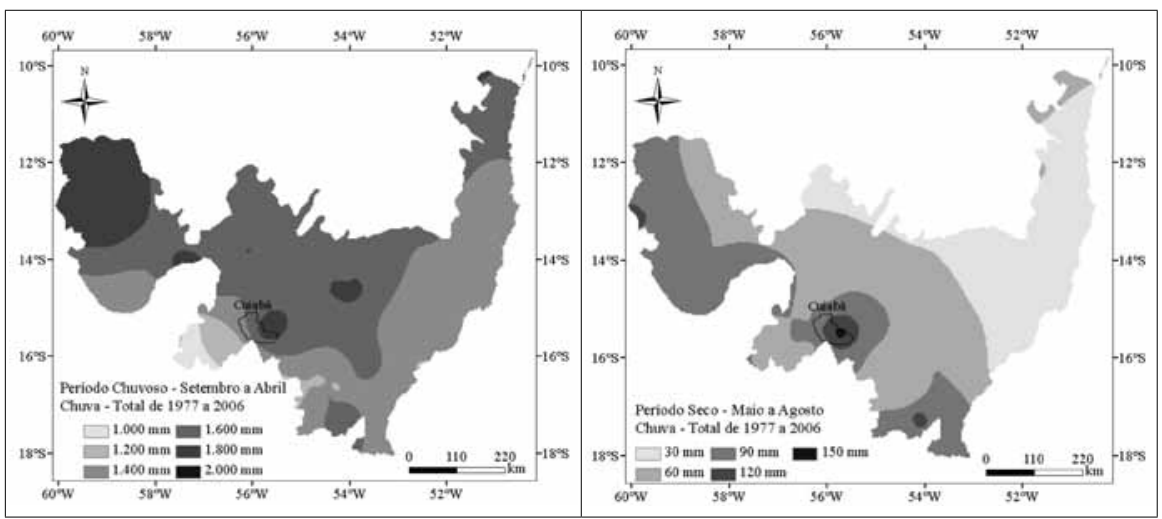

Figura 9 - Precipitação pluviométrica total para o período chuvoso (setembro a abril) e seco (maio a agosto), para o estado de Mato Grosso, referente ao período histórico de 1977 a 2006.

Índice de Anomalia de Chuva - IAC

A utilização do IAC permitiu identificar padrões ou mudança no comportamento da chuva, além de avaliar a distribuição espacial do evento. Com a aplicação dos IACs determinaram-se os anos que se caracterizam como úmidos e secos.

As Figuras 10, 11 e 21 ilustram os IACs da estação do ano verão no estado, referentes, respectivamente, aos meses de janeiro, fevereiro e dezembro, época cuja característica é de alto índice de pluviosidade. Verifica-se na Figura 10 que o IAC do mês de janeiro teve 12 anos úmidos e 15 anos secos, com o ponto de maior inflexão dos anos úmidos ocorrendo no ano de 2004, caracterizado como muito chuvoso (Quadro 1), e o maior dos anos secos como o ano de 1993, caracterizado como extremamente seco (Quadro 1). O mês de fevereiro, Figura 11, teve 12 anos úmidos e 17 anos secos, tendo o maior IAC de anomalia de chuva ocorrido em 1980, ano caracterizado como extremamente chuvoso, e o maior IAC dos anos secos ocorreu em 2005, sendo um ano caracterizado como muito seco (Quadro 1). Já no mês de dezembro ocorreram 12 anos úmidos e 16 anos 
secos, com o ponto de maior inflexão do período chuvoso no ano de 2001, e o maior ponto de inflexão dos anos secos no ano de 1985, caracterizado como extremamente seco (Quadro 1).

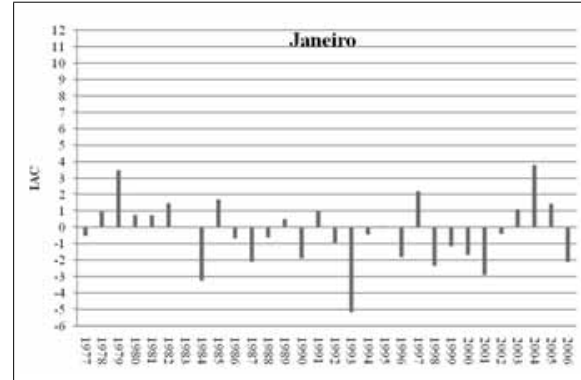

Figura 10 - IAC do mês de janeiro para o bioma Cerrado do estado de Mato Grosso.

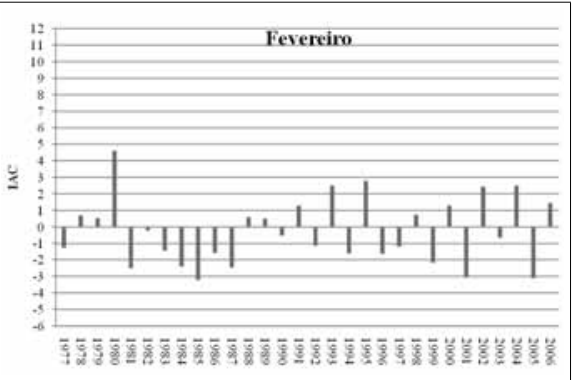

Figura 11 - IAC do mês de fevereiro para 0 bioma Cerrado do estado de Mato Grosso.

Os meses março, abril e maio, figuras 12, 13 e 14, respectivamente, representam os IACs da estação do outono. Pode-se observar-se que o mês de março (Figura 12) teve 11 anos úmidos contra 18 anos secos, sendo o ano de 1981 o ano de inflexão de maior umidade, e o maior IAC das anomalias secas ocorreu no ano 2004 (Quadro 1). O mês de abril (Figura 13) obteve 11 anos úmidos e 18 anos secos. Para o mês de maio, Figura 14, o IAC indicou 12 anos úmidos e 18 anos secos.

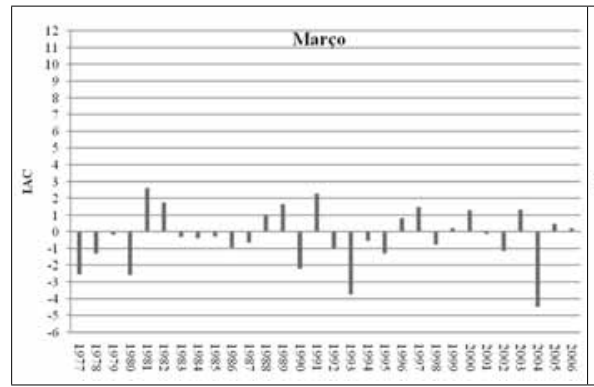

Figura 12 - IAC do mês de março para o bioma

Cerrado do estado de Mato Grosso.

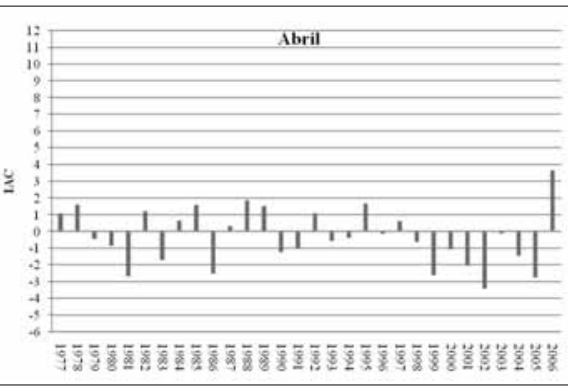

Figura 13 - IAC do mês de abril para o bioma Cerrado do estado de Mato Grosso.

O trimestre representado pelos meses de junho, julho e agosto, figuras 15, 16 e 17, respectivamente, é considerado a estação inverno em Mato Grosso, quando ocorreram 27 anos chuvosos e 60 anos secos. 


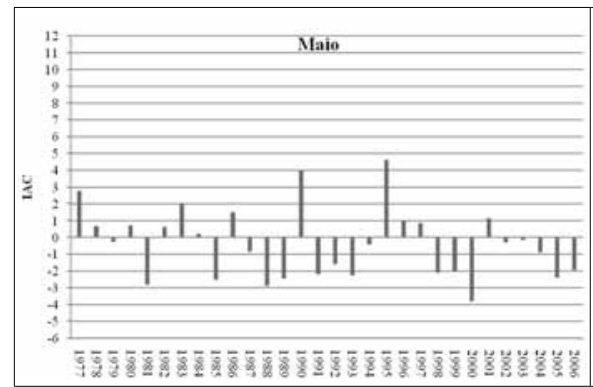

Figura 14 - IAC do mês de maio para o bioma Cerrado do estado de Mato Grosso.

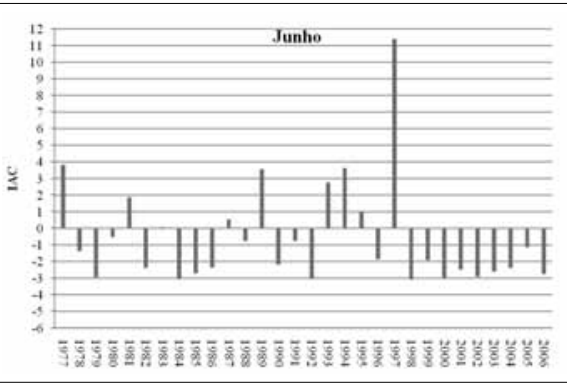

Figura 15 - IAC do mês de junho para o bioma Cerrado do estado de Mato Grosso.

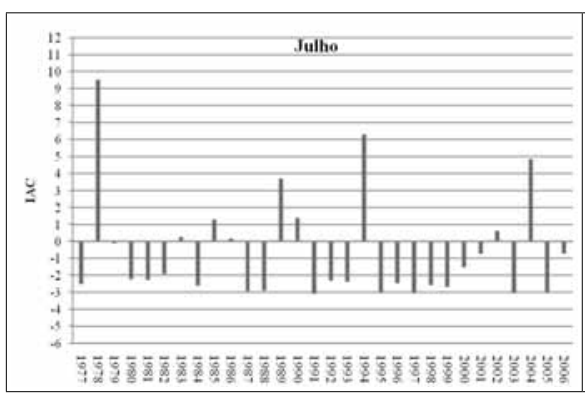

Figura 16 - IAC do mês de julho para o bioma Cerrado do estado de Mato Grosso.

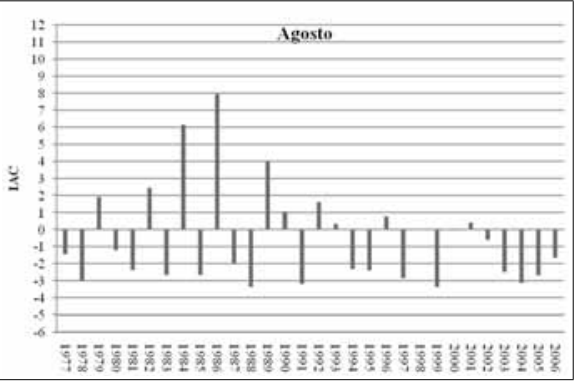

Figura 17 - IAC do mês de agosto para o bioma Cerrado do estado de Mato Grosso.

O trimestre de setembro, outubro e novembro, mostrado nas figuras 18, 19 e 20, respectivamente, é a estação da primavera em Mato Grosso. Os IACs demonstram que ocorreram 33 anos chuvosos e 53 anos secos para esta estação. Verifica-se na Figura 18, que no IAC do mês de setembro houve 12 anos úmidos e 17 anos secos, com o ano de maior inflexão dos anos chuvosos ocorrendo em 1992 (Quadro 1), e o maior dos anos secos, em 1988 (Quadro 1). Para o mês de outubro, o IAC indicou 11 anos úmidos, 18 anos secos, sendo que a maior anomalia úmida ocorreu no ano de 2006, classificado como muito chuvoso (Quadro 1) e a maior anomalia seca, em 1979. Já na Figura 20, relativa ao mês de novembro, observa-se que o IAC apontou 10 anos úmidos, com o ano de 1983 de maior inflexão e 18 anomalias de anos secos, sendo os anos de 1990 e 1991 as inflexões dos anos secos. 


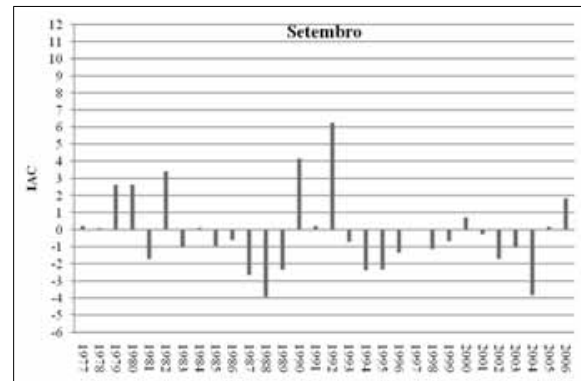

Figura 18 - IAC do mês de setembro para 0 bioma Cerrado do estado de Mato Grosso.

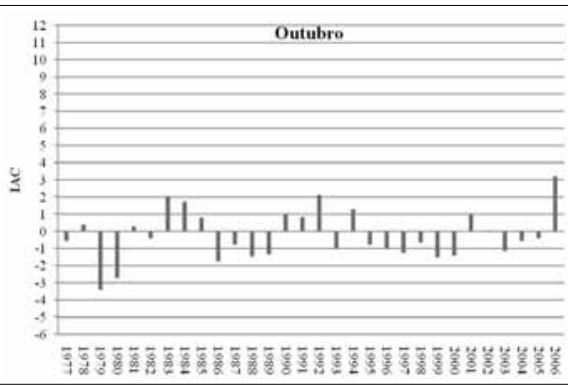

Figura 19 - IAC do mês de outubro para 0 bioma Cerrado do estado de Mato Grosso.

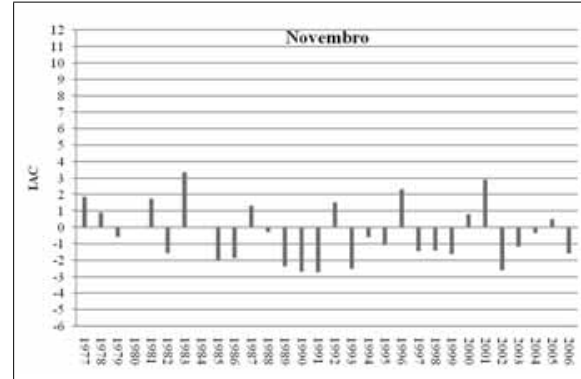

Figura 20 - IAC do mês de novembro para 0 bioma Cerrado do estado de Mato Grosso.

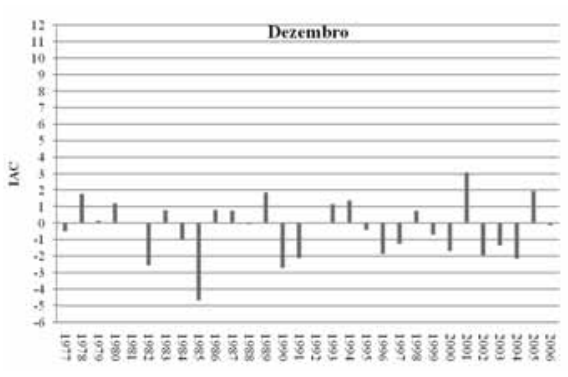

Figura 21 - IAC do mês de dezembro para 0 bioma Cerrado do estado de Mato Grosso.

Considerações finais

Neste trabalho, analisou-se a distribuição dos índices pluviométricos, utilizando cálculo do Índice de Anomalia de Chuva (IAC), para a verificação dos períodos secos ou úmidos no bioma Cerrado do estado do Mato Grosso.

Os resultados da distribuição pluviométrica mostram uma grande variação nos totais precipitados no bioma do Cerrado mato-grossense, sendo que os extremos noroeste e norte têm os maiores volumes de chuvas e o sul da área de estudo, os menores índices pluviométricos. Na análise das chuvas, comprovou-se que os maiores índices pluviais concentraramse nas estações da primavera e verão, outubro a março, correspondendo a cerca de 87,5\% do volume precipitado para média histórica de 1977 a 2006. Já abril e setembro são meses que antecedem a mudança do 
comportamento hídrico em Mato Grosso. Com a aplicação do IAC para o período de análise, conclui-se que ocorreram mais eventos negativos, ou seja, anos secos.

\section{Referências}

AGÊNCIA NACIONAL DE ÁGUAS. Brasília: ANA, 2010. Hidroweb. Disponível em: http://www.ana.gov.br. Acesso em: 11 dez. 2009.

ARAÚJO, L. E.; MORAES NETO, J. M.; SOUSA, F. A. S. Classificação da precipitação anual e da quadra chuvosa da bacia do rio Paraíba utilizando índice de Anomalia de Chuva (IAC). Revista Ambiente \& Água - Na interdisciplinary Journal of Applied Science: Taubaté, v. 4, n. 3, p. 93-110, 2009.

BRAZ, R. L. et al. Uso de séries históricas e técnicas de sig no estudo da distribuição temporal e espacial da pluviosidade na bacia barra seca localizada ao norte do estado do Espírito Santo. In: Anais do XI Encontro Latino Americano de Iniciação Científica, São José dos Campos, v. 14, p. 54-57, 2007.

COUTINHO, A. C. Dinâmica das queimadas no estado do Mato Grosso e suas relações com as atividades antrópicas e a economia local. Tese (Doutorado em Ciência Ambiental -Procam) - Universidade de São Paulo, São Paulo, 2005.

IBGE. Mapas IBGE. Rio de Janeiro: IBGE 2009. Disponível em: http://www.ibge. gov.br/mapas_ibge/. Acesso em: 8 mar. 2010.

NIMER, E. Climatologia do Brasil. Rio de Janeiro: Fundação IBGE, 1989.

ROSA, D. B. et al. A distribuição espacial das chuvas na porção Centro-Oeste do estado de Mato Grosso-Brasil. Revista Eletrônica da Associação dos Geógrafos Brasileiros. Três Lagoas, MS, v. 1, n. 5, p. 93-110, 2007.

ROOY, M. P. VAN. A Rainfall Anomaly Index Independent of Time and Space. Notes, 14, 1965.

Francisco Fernando Noronha Marcuzzo - Mestre em Irrigação e Drenagem pela Universidade Estadual Paulista. Doutorado e Pós-Doutorado em Engenharia Hidráulica pela Universidade de São Paulo. Engenheiro e Pesquisador em Geociências- CPRM/SGB - (Companhia de Pesquisa de Recursos Minerais / Serviço Geológico do Brasil - Empresa Pública de Pesquisa do Ministério de Minas e Energia).

Hudson Moraes Rocha - Geógrafo, Mestrando de Geografia pela Universidade Federal de Goiás.

Denise Christina de Rezende Melo - Engenheira, Pesquisadora em Geociências, CPRM/SGB - (Companhia de Pesquisa de Recursos Minerais/Serviço Geológico do Brasil - Empresa Pública de Pesquisa do Ministério de Minas e Energia). 